DOE Technical Report No. DOE/PC/88921.2

Second Quarterly Report on Research Grant No. DE-FG22-88PC88921

Title: SPIN-MAPPING OF COAL STRUCTURES WITH ESE AND ENDOR

Principal Investigators: R. L. Belford and R. B. Clarkson

Institution: University of Illinois at Urbana-Champaign

Date: March 1, 1989

USIDOE Patent Clearance is not required prior to publication of this document.

\title{
ABSTRACT
}

The resolution of EPR spectroscopy is considerably increased at $Q$ - and W-band microwave frequency ranges. Anisotropic interactions of the $\mathrm{g}$ - and A-matrices will be resolved in previously unresolved systems such as coal macerals. The coupling of the spin angular momentum of unpaired electrons and the orbital angular momentum of sulfur atoms is a major contributor to the anisotropy displayed by free radical sulfur-containing organic species. Samples consisting of sulfur-containing heterocyclic compounds adsorbed onto silica-alumina catalyst surfaces were used as models in examining the anisotropic interactions associated with sulfur-containing molecules. Characterization of the disordered solid EPR and ENDOR spectra of the models allowed the development of analytical techniques capable of examining highly anisotropic systems. The resolved hyperfine and g-matrices can be used to analyze and predict spectral features from the direct analysis of coal maceials that have high organic sulfur content.

\section{GENERAL SUMMARY}

Our Laboratory is presently engaged in developing a method to model sulfur-containing compounds in whole coal. It has been established that most of the organic sulfur in coal exists in the form of aromatic groups known as thiophenes. Sulfur-containing aromatic compounds such as thiophene, tetraphenylthiophene and thianthrene were adsorbed onto silica-alumina catalyst surfaces were used as models to emulate coal's anisotropic nature and abundance of unpaired electron spin density.

Unpaired spin density near sulfur atoms produces an a nisotropy in the g matrix of the system which is detectable using EPR techniques. Studying the previously mentioned model systems has resulted in the development of a method which is able to analyze the anisotropic interactions of sulfur related g-matrix anisotropy. Characteristic hyperfine interactions of the unpaired spins with nearby protons were also obtained. The information allowed conclusions to be drawn about the geometric and physical characteristics of the sulfur containing compounds used as models. The characteristic hyperfine information of each thiophene compound were added to a data base from which analyses of spectral fealures of coals macerals can be made.

The spectroscopic lechniques used were Electron Paramagnetic Resonance (EPR). Electron-Nuclear Double Resonance (ENDOR). EPR spectroscopy is a well established method to characterize g-matrix anisotropy in transition metal compounds. With increased resolution, EPR has become very useful for characterizing the small but still detectable g-matrix anisotropy in organic systems slich as coal and the model systems for coal. ENDOR spectroscopy involves the inducement of NMR transitions of the nearby protons while delecting them with an EPR detection scherre which is several orders of magnitude more sensitive than using a NMR

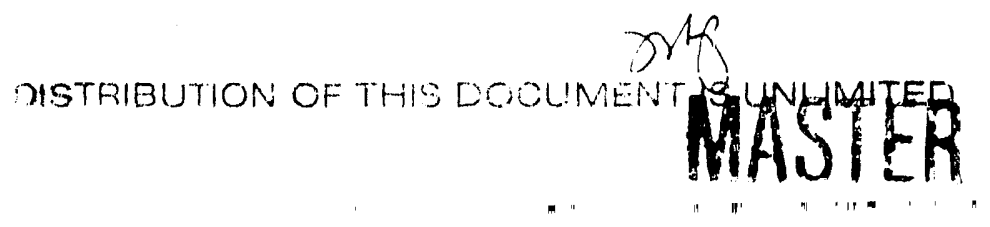


detection scheme. Analysis of the ENDOR spectra produced hyperfine information which is characteristic of the se sulfur-containing systems. This information will be needed to resolve anisotropic hyperfine spectral fealures attributable to sulfur content in the analysis of coal macerals.

\section{OBJECTIVES AND BACKGROUND}

The analysis of coal macerals has posed a problem with resolution when using EPR spectroscopy. Coal samples examined at the traditional $X$-band microwave excitation frequency typically exhibit a single, nearly symmetric EPR absorption line that is too featureless to analyze uniquely. At $\mathrm{W}$-band $(95 \mathrm{GHz})$ however, anisotropic interactions in the $\mathrm{g}$-matrix become apparent. In the laboratory of Professor Klaus Mobius at the Free University in West Germany, the first $W$-band EPR experiment on coal was performed. The results unambiguously revealed the axial character of the system. This data has also been corroborated in our laboratory with a newly developed $W$-b and spectrometer. The anisotropy of the g-matrix increases the chance of arriving at a unique theoretical description of the coal system.

In order to properly simulate the spectra obtained from coal-derived samples it becomes necessary start from fundamental building blocks of information. Sulfur containing systems inside coal are of special interest because of the concern over high sulfur content. Information about simpler sulfur-containing molecules is needed to use in assembling the simulated spectra for coal samples. Thiophenes become the focus of this research effort because most organic sulfur inside coal is in the form of thiophenes.

It was necessary to develop a consistent method to analyze the spectra obtained from the model systems with the emphasis on the anisotropic effects upon the EPR spectrum caused by sulfur. Thianthrene, a sulfur containing heterocyclic compound was a good model to begin with because it displays observable anisotropic fealures attribulable $10 \mathrm{~g}$-matrix anisotropy in its $X$. band EPR signal when it is adsorbed onto the silica-alumina surface. Through the analysis of thianthrene's complex EPR and ENDOR spectra an analytical method of simulating disordered solid systems was developed. Since the anisotropic interactions in thianthrene are very complex, the method is applicable to highly disordered systems in general and systems with less anisotropy. The focus of future experiments will be to apply this developed method to thiophenes. We plan to characterize several thiophene class compounds that resemble the possible configurations of sulfur in coal.

Improvements must still be made on sample preparation techniques in order to obtain reproducible and reliable data from the analysis of the model systems. New surface treatment methods are currently being attempted to increase the EPR and ENDOR signals.

\section{EXPERIMENTAL PROCEDURES}

The model system that worked best for the thianthrene experiment was produced by first calcining Houdry-M46 brand silica-alumina under vacuum and introducing the thianthrene in the gas phase. The samples were prepared in quartz $X$-band EPR sample. EPR was performed on a Varian 12" Century Series EPR spectrometer with ENDOR capabilites. ENDOR spectra were taken at incremented magnetic field positions within the field range covered by the EPR signal. 
The g-matrix was obtained by fitting the experimental EPR spectrum with a computer generated EPR spectrum. The parameters were optimized by using a auto-iterative routine that minimizes a least squares response function. The hyperline matrices were obtained by optimizing the fit between the experimental ENDOR spectra and computer generated ENDOR spectra at various field positions.

\section{RESULTS AND DISCUSSION}

The results are shown in Figures 1 and $2(a-c)$. Figure 1 shows a comparison of the experimental EPR spectra and the best fil calculated by using the method of Belford (Ref. [1]). The important parameters used in the calculation are $g[1]=2.00146, g[2]=2.00744, g[3]=$ 2.01261. Figure 2 compares experimental to calculated ENDOR spectra at the three field positions. There is a clear shift in hyperfine frequencies and their intensities observed between the extreme field values. Different molecular orientations relative to the applied magnetic field contribute differently to the ENDOR spectrum at different field values. This allowed some degree of angle selection at X-band although there is considerable overlap between the three turning points of the EPR spectrum. The best fit of the ENDOR spectra at all three field values required the assigning of the diagonal matrix g-values to be $g[x]=2.00744, g[y]=$ $2.01261, g[z]=2.00146$.

\section{CONCLUSIONS AND RECOMMENDATIONS}

One conclusion that can be drawn is the assignment of the diagonal g-matrix elements $g[x]$, $g[y], g[z]$ to the quantitative values calculated for the system and the consequent assignment of the directions of the $g$-values relative to the molecular geometry of thianthrene attached to the catalyst surface. Figure 3 shows the present assignment for the directions of the numerical $\mathrm{g}$-values. Optimization of the ENDOR parameters must be continued to improve the fit between the calculated spectra and the experimental spectra to support this conclusion and to draw new conclusions about the model system.

The analysis described must be completed for thiophene compounds since thiophenes are better models for sulfur centers in coal. The preparation of thiophene models have been slightly more difficult in the past but have improved recently and better spectral signal to noise has been obtained. The computer algorithm used could also be improved by adding higher order correction terms to the spin Hamiltonian.

\section{REFERENCES}

1. Rothenberger, K. S., Nilges, M. J., Altman, T. E., Belford, R. L, Froncisz, W., and Hyde, J. S., Chem. Phys. Lett., 124, 295 (1986).

(This work also has been reported to the Center for Research on Sulfur in Coal in the State of Illinois, which has provided additional assistance.) 
Figure 1. The solid line is the experimental EPA spectrum and the dashed line is the calculated EPR spectrum. The spectrum was laken at $T=120 \mathrm{~K}$.

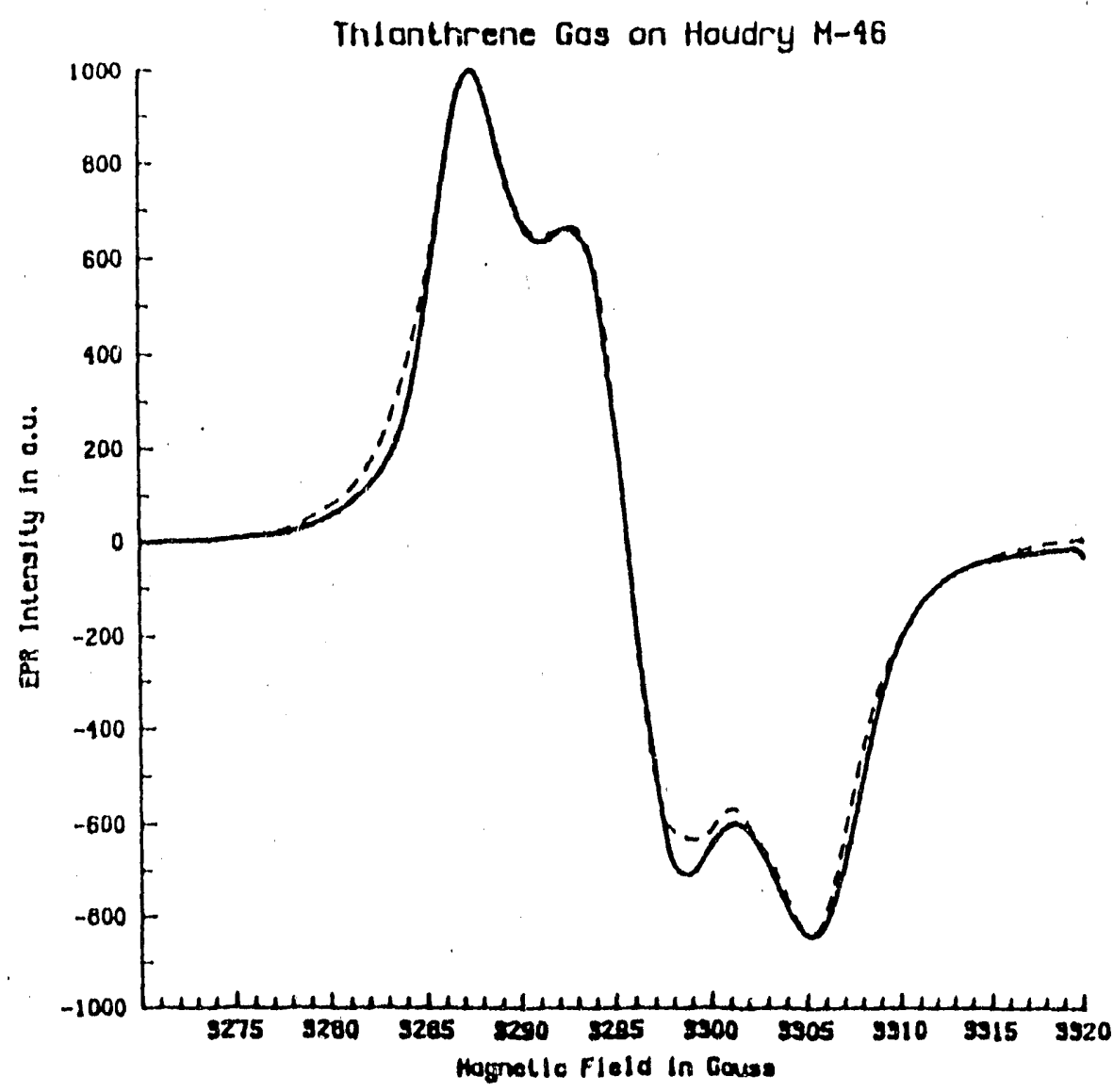

DISCLAIMER

This report was prepared as an account of work sponsored by an agency of the United States Government. Neither the United States Government nor any agency thereof, nor any of their employees, makes any warranty, express or implied, or assumes any legal liability or responsibility for the accuracy, completeness, or usefulness of any information, apparatus, product, or process disclosed, or represents that its use would not infringe privately owned rights. Refer" ence herein to any specific commercial product, process, or service by trade name, trademark, manufacturer, or otherwise does not necessarily constitute or imply its endorsement, recommendation, or favoring by the United States Government or any agency thereof. The views and opinions of authors expressed herein do not necessarily state or reflect those of the United States Government or any agency thereof. 
Figure 2. a) ENDOR spectrum al 3290 Gauss and corresponding calculated ENDOR spectrum.

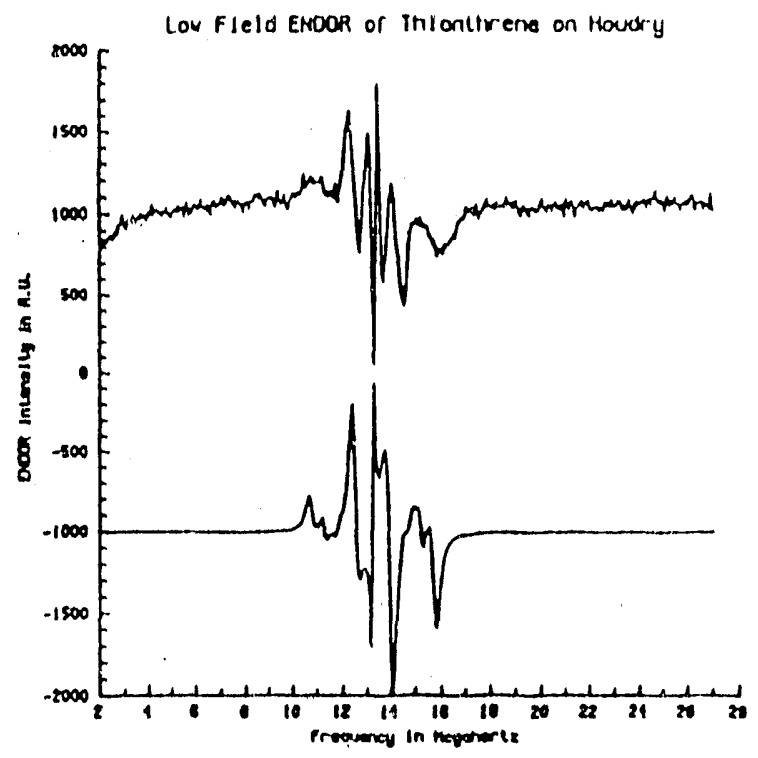

Figure 2. b) ENDOR spectrum at 3300 Gauss and calculated spectrum.

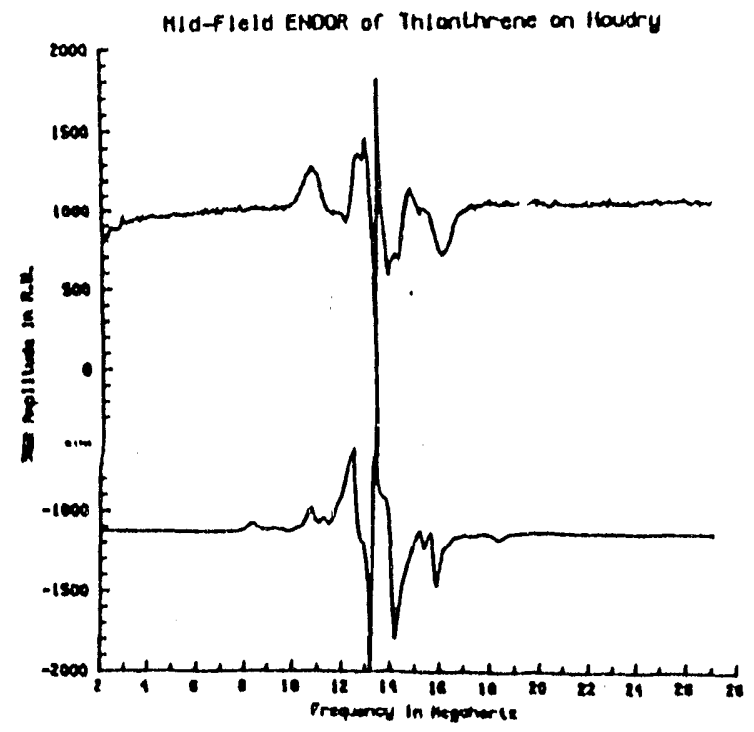


Iigume 2. c) ENDOR spectrum al 3307 Gauss and calculaled spectrum.

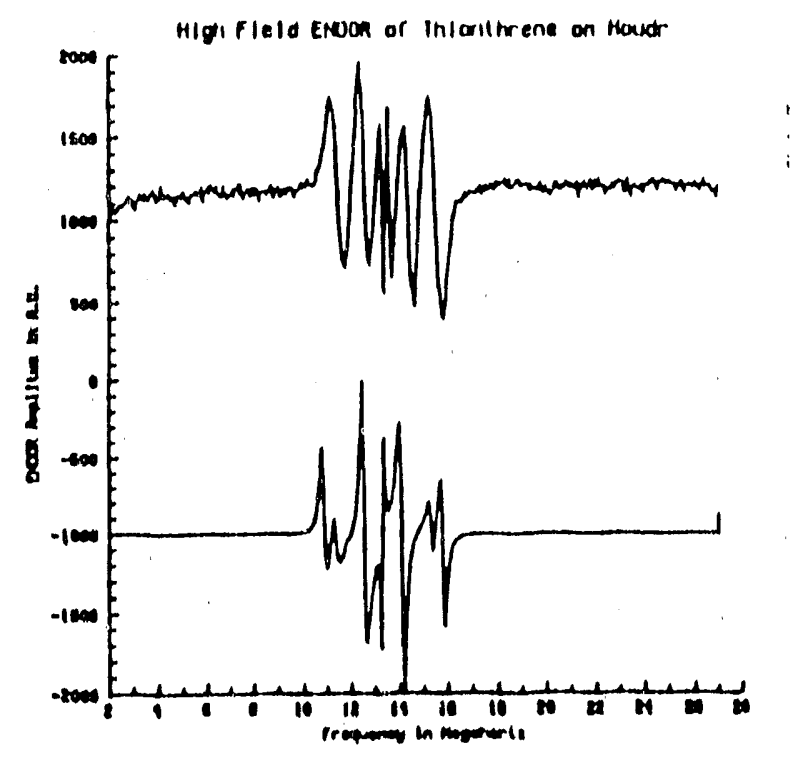

Figure 3. Thianthrene $\left(C_{12} \mathrm{H}_{8} S_{2}\right)$ molecule where $g|x|=2.00744, g|y|=2.01261, g|z|=$ 2.00146. $\mathrm{g}(\mathrm{z})$ is coming out of the plane of the page.

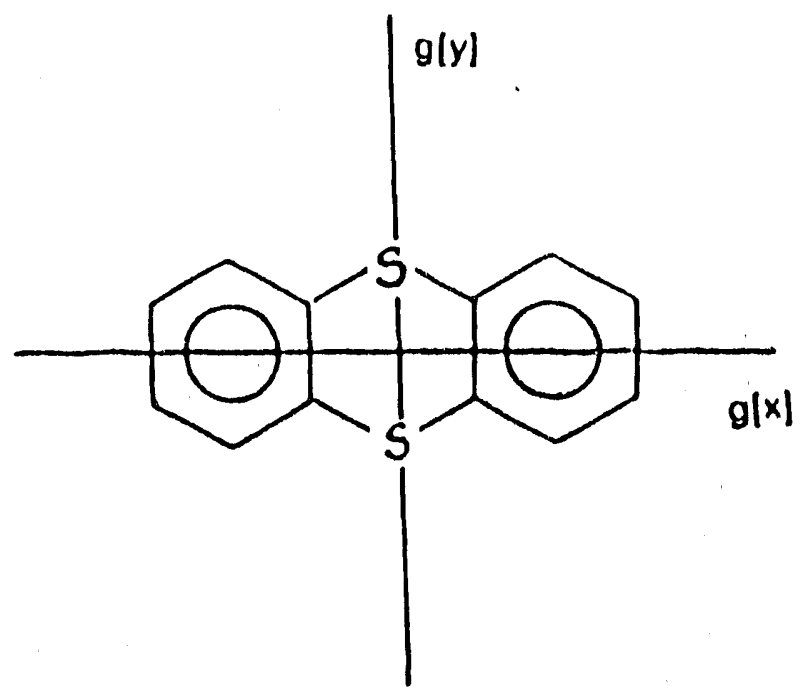



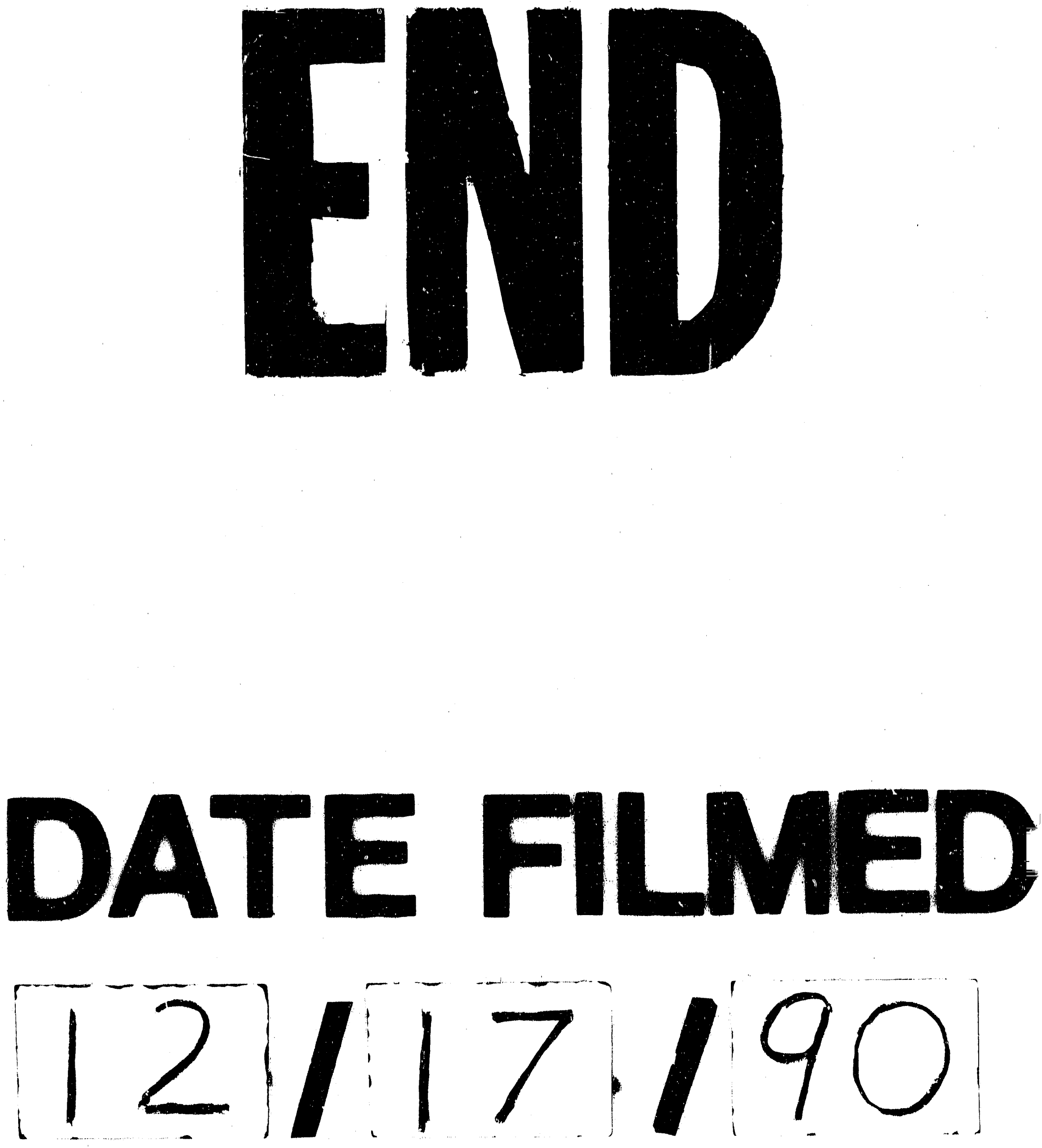
